\title{
THE EFFECT OF PSEUDOPREGNANCY AND 'PSEUDOPARTURITION' ON THE KININ SYSTEM IN THE RAT
}

\author{
JUDITH SENIOR AND E. T. WHALLEY \\ Postgraduate School of Studies in Pharmacology, \\ University of Bradford, Bradford 7, Yorkshire
}

(Received 2nd October 1973)

\begin{abstract}
Summary. The kininogen content of rat plasma during late pseudopregnancy was found to increase, showing similar but less marked changes to those found in normal pregnancy and parturition. The kininase values during pseudopregnancy showed no significant change from the non-pregnant control value.

During the condition of 'pseudoparturition', in which the fetuses were killed in utero between Days 12 and 15 of pregnancy and the placentae were delivered on Day 21 or 22, the kininogen content of the plasma increased. The increase in plasma kininogen during 'pseudoparturition' was more marked than in pseudopregnancy. The kininase activity during 'pseudoparturition' was significantly lower than that found in non-pregnant female rats; this finding is similar to that observed in pregnant rats.

It appears from these findings that the changes in the kinin system components during pregnancy are not wholly dependent on the fetoplacental unit.
\end{abstract}

\section{INTRODUCTION}

Earlier studies in this laboratory have shown that the concentration of plasma kininogen rises with advancing gestation in the rat (McCormick \& Senior, 1973). On Day 22 of pregnancy, the plasma kininogen level is approximately twice the value found in the non-pregnant female. Whilst the kinin precursor level is raised as gestation advances, the kinin-inactivating enzymes, the kininases, show a decreased activity towards the end of pregnancy (McCormick \& Senior, 1972).

The circulating levels of oestrogen have also been shown to affect the kinin system components (McCormick \& Senior, 1971). When the oestrogen levels are raised by the administration of exogenous oestrogen, there is a rise in the kininogen content of plasma but the kininase activity is lowered.

These findings have led us to consider how far the feto-placental unit is involved in the changes which occur in the kinin system components during pregnancy in the rat. The present study was undertaken to determine the 
effect of pseudopregnancy and 'pseudoparturient' conditions upon the circulating levels of kininogen and kininase activity in rat plasma.

\section{METHODS}

Mature virgin female rats of the CSE strain, weighing 200 to $250 \mathrm{~g}$, were used and were housed in plastic wire mesh floor cages in light- (07.00 to 19.00 hours) and temperature-controlled rooms. They were allowed free access to food and water.

\section{Pseudopregnancy}

Pseudopregnancy was induced by mating pro-oestrous female rats with vasectomized male rats. Day 1 of pseudopregnancy was characterized by the presence of a vaginal plug. Prolongation of pseudopregnancy of up to 23 days was achieved using the uterine scratch technique of De Feo (1963). Pseudopregnancy was characterized by persistence of a dioestrous vaginal smear (Long \& Evans, 1922) and the presence of deciduomata at autopsy after blood sampling.

\section{'Pseudoparturition'}

The day on which spermatozoa were found in the morning vaginal smear was designated Day 1 of pregnancy. Between Days 12 and 15 of pregnancy, rats were anaesthetized using a halothane-oxygen mixture and the abdomen was palpated. The fetuses were picked up through the abdominal wall without any incision and the amniotic sacs were burst by steady pressure (Newton, 1935). This was found to be sufficient to destroy the fetuses but to leave the placentae intact. The day of delivery of the placentae was indicated by the uterus being empty at autopsy.

\section{Kininogen estimations}

The concentrations of plasma kininogen were determined using modified methods of Diniz \& Carvalho (1963) and McCormick \& Senior (1973). In the current series of experiments, all the samples were maintained at $4^{\circ} \mathrm{C}$ throughout the procedure. Bioassay was performed using the isolated rat uterus.

\section{Kininase activity}

Kininase activity was estimated by incubating $0.05 \mathrm{ml}$ plasma with $5 \mu \mathrm{g}$ synthetic bradykinin (Sandoz) in $0.4 \mathrm{ml}$ of $0.2 \mathrm{M}$-tris buffer, $\mathrm{pH} 7.4$, at $37^{\circ} \mathrm{C}$ for $5 \mathrm{~min}$. Assay of residual activity was performed using the isolated guineapig ileum as previously described (McCormick \& Senior, 1972). The kininase activity was expressed as the percentage destruction of the bradykinin by the plasma kininases under the experimental conditions.

\section{RESULTS}

\section{Pseudopregnancy}

The levels of kininogen and the kininase activity of rat plasma during late 
pseudopregnancy are shown in Text-fig. 1. The kininogen results are expressed as $\mu \mathrm{g}$ bradykinin equivalents per $\mathrm{ml}$ plasma. There is some indication that the kininogen levels increase with the advancing stage of pseudopregnancy. This increase is only significant $(P<0 \cdot 05)$, however, when the Day-21 $(1 \cdot 79 \pm 0 \cdot 18$ $\mu \mathrm{g}$ equiv./ml) or Day-22 $(1.79 \pm 0.15 \mu \mathrm{g}$ equiv. $/ \mathrm{ml})$ value is compared with the non-pregnant control value $(1 \cdot 20 \pm 0.23 \mu \mathrm{g}$ equiv. $/ \mathrm{ml})$. It can be seen that by Day 24 of pseudopregnancy, the kininogen levels had returned to those levels found in the non-pregnant control group.

Text-figure 1 also shows the kininase activity of rat plasma during pseudopregnancy. The kininase activity does not show any significant difference from the activity seen in the non-pregnant control group. The activity does,

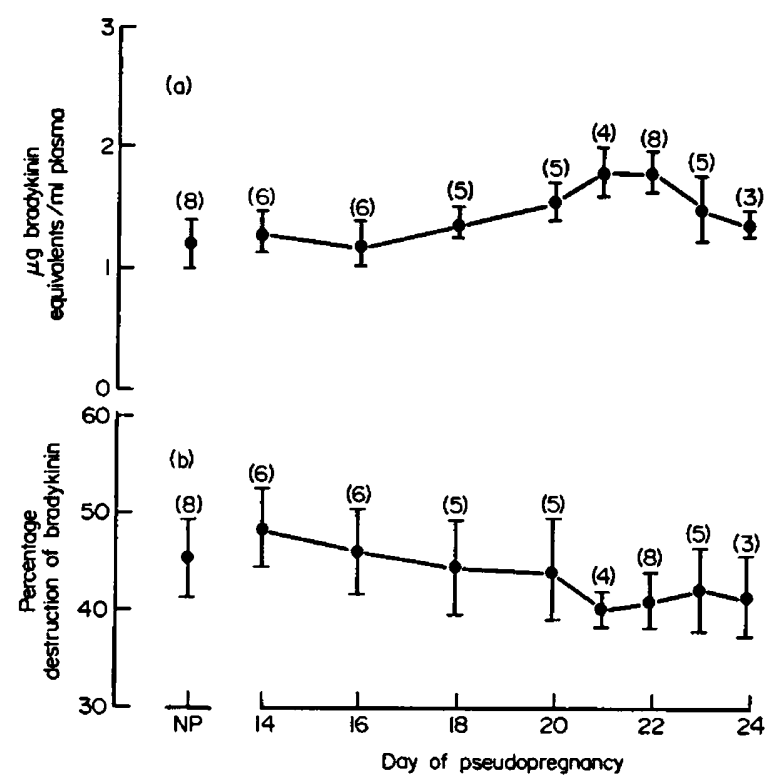

Text-FIG. 1. The kininogen content (a) and the kininase activity (b) of rat plasma during pseudopregnancy. NP indicates the control value obtained for non-pregnant rats. Vertical lines indicate standard errors and the number of observations are given in parentheses.

however, show a tendency to decrease towards the end of pseudopregnancy, when the kininogen levels are increasing.

\section{'Pseudoparturition'}

During the pseudoparturient condition, an increase in the plasma level of kininogen was found to occur (Text-fig. 2). The greatest rise in plasma kininogen occurred from Day 21 of gestation onwards. Maximum levels of kininogen were obtained 1 day after the delivery of the placentae but 3 days later the levels had almost returned to those found in the non-pregnant control group. The actual time of delivery of the placentae could not be determined and it was presumed that they had been eaten as delivery took place. No active abdominal 
contractions were observed and delivery was taken as the absence of placentae in the uterus. Delivery of the placentae always occurred late on Day 21 or Day 22 of gestation. The plasma kininogen levels during this pseudoparturient condition were significantly higher from Day 20 after mating onwards and on Day 1 post partum than those of the non-pregnant control group $(P<0.001)$.

The kininase activity during the pseudoparturient condition is also shown in Text-fig. 2. The kininase activity of plasma was significantly lower $(P<0 \cdot 05)$ than that found in the non-pregnant control group. This low enzyme activity was maintained after the delivery of the placentae.

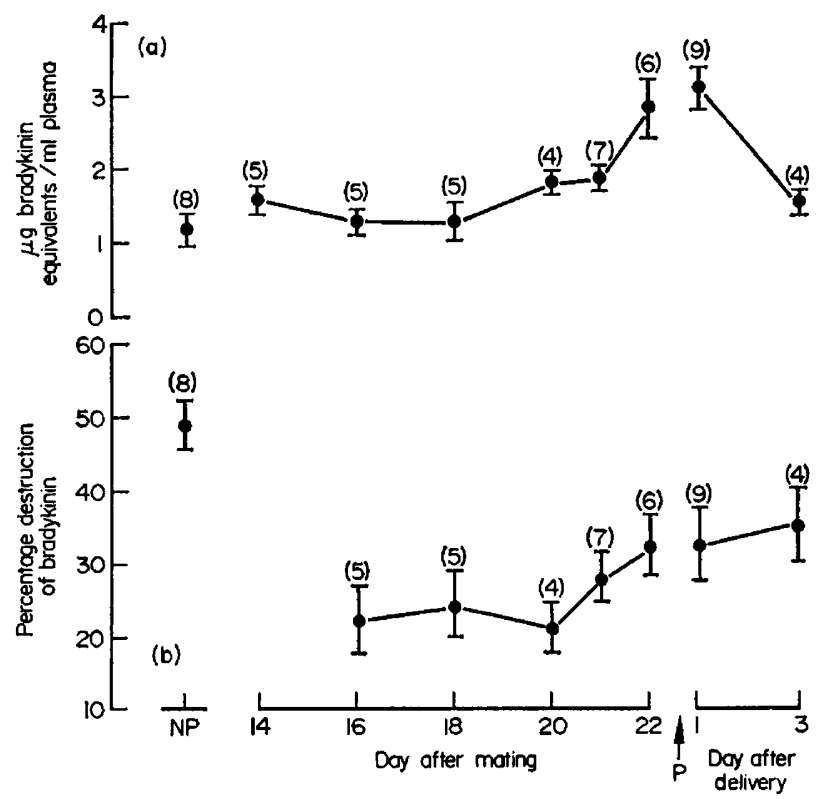

Text-Fig. 2. The kininogen content (a) and the kininase activity (b) of plasma during the 'pseudoparturient' condition in rats. $N P=$ non-pregnant rats; $P=$ parturition of the placentae. Vertical lines indicate standard errors and the number of observations are given in parentheses.

\section{DISCUSSION}

The method used to determine the bradykininogen content of plasma is similar to that previously used in this laboratory (McCormick \& Senior, 1973) with the exception that all the samples were maintained at $4^{\circ} \mathrm{C}$. This has resulted in lower estimations than those previously reported by our laboratory, a finding which has also been shown by Habal \& Movat (1972) when investigating the kininogens of human plasma. Maintenance of the experimental conditions at room temperature or low temperature $\left(-70^{\circ} \mathrm{C}\right)$ produced higher kininogen values than when the conditions were kept at $4^{\circ} \mathrm{C}$.

During prolonged pseudopregnancy, the kininogen content has been shown to increase significantly. This time in pseudopregnancy was chosen as the greatest changes in the kininogen content of plasma during pregnancy 
occur from Day 20 onwards (McCormick \& Senior, 1973). It seemed possible that the increase in kininogen content during pregnancy could be due to the increase in plasma oestrogen levels which occur around this time. Yoshinaga, Hawkins \& Stocker (1969) have shown that there is a surge of oestrogen from the ovaries of the rat from Day 20 of gestation, reaching a climax on Day 22. We have shown that an increase in oestrogen levels results in a significant increase in the rat plasma kininogen values (McCormick \& Senior, 1971). It seems, therefore, that the pseudopregnancy values for kininogen content support the theory that the ovary is, at least in part, responsible for the changes in the kininogen content of the plasma which occur during normal pregnancy. This theory is also supported by the work of Bast \& Melampy (1972), who have shown that a rapid rise in the LH level occurs in pregnancy and prolonged pseudopregnancy around Day 20 which may also be related to the increase seen in 20 $\alpha$-hydroxysteroid dehydrogenase activity. In both reproductive states this should result in an increased oestrogenic effect.

Changes in the kininase levels during prolonged pseudopregnancy are not significantly different from the control value, indicating that either the kininase activity is dependent on the presence of the feto-placental unit or that the hormonal changes found in pseudopregnancy are not sufficiently marked to be effective. Plasma kininase activity can be depressed by the presence of oestrogens (McCormick \& Senior, 1972). The fall in activity, however, is not so marked as that shown in pregnancy.

During the condition of pseudoparturition, the kininogen levels in plasma again showed a significant increase from Day 20, the increase being more marked than that shown in prolonged pseudopregnancy. In this experiment, the fetus had been destroyed and the placenta remained attached to the uterus but failed to develop further after the death of the fetus. It appears, therefore, that the ovary again contributed mainly to the changes in kininogen content, as the placental function must have been diminished or non-existent. As in the case of normal parturition, the kininogen values for 'pseudoparturition' are highest on the day following delivery. In rats, this post-parturient level of kininogen following normal pregnancy can be attributed to the delay in plasma kininogen levels in following the oestrogen levels (McCormick \& Senior, 1973); it appears that the same could be true for 'pseudoparturition'. The kininase activity during 'pseudoparturition' is significantly lower than the non-pregnant value and is similar to the pattern found in normal pregnancy (McCormick \& Senior, 1972). It appears that the presence of the uterine contents, although non-viable, may have some effect on kininase activity as these changes are not seen during pseudopregnancy. It is interesting to note that in 'pseudoparturition', as in normal parturition, the kininase activity has not returned to normal values 3 days after the delivery of the placentae.

These experiments seem to indicate that the kininogen content of rat plasma during pregnancy may be under the influence of the ovarian hormones but the kininase activity changes during pregnancy are only found in the presence of the feto-placental unit. The ratio of the oestrogenic hormones to the progestagenic hormones may also influence the components of the kinin system and work to investigate this effect is in progress. 


\section{ACKNOWLEDGMENT}

We should like to thank Dr G. M. Smith (Sandoz Products Limited) for the gift of synthetic bradykinin.

\section{REFERENCES}

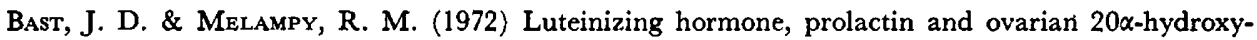
steroid dehydrogenase levels during pregnancy and pseudopregnancy in the rat. Endocrinology, 91, 1499.

De FEo, V. J. (1963) Temporal aspect of uterine sensitivity in the pseudopregnant or pregnant rat. Endocrinology, 72, 305.

Diniz, G. R. \& Garvalho, I. F. (1963) A micromethod for determination of bradykininogen under several conditions. Ann. N.Y. Acad. Sci. 104, 77.

Habal, M. H. \& Movat, H. Z. (1972) Kininogens of human plasma. Res. Comm. Chem. Path. $\mathfrak{E}$ Pharmac. 4, 477.

Long, J. A. \& Evans, H. M. (1922) The oestrous cycle in the rat and its associated phenomena. Mem. Univ. Calif. 6.

McCormick, J. T. \& Senior, J. (1971) Effect of sex hormones on the concentrations of plasma kininogen in the female rat. Br. F. Pharmac. Chemother. 43, 421.

McCormick, J. T. \& Senior, J. (1972) The effect of the oestrous cycle, pregnancy and reproductive hormones on the kininase activity of rat blood. F. Reprod. Fert. 30, 381.

McCormick, J. T. \& Senior, J. (1973) Plasma kininogen levels in rat pregnancy. Br. F. Pharmac. Chemother. (in press)

Newton, W. H. (1935) 'Pseudo-parturition' in the mouse and the relation of the placenta to postpartum oestrus. F. Physiol., Lond. 84, 196.

Yoshinaga, R., Hawkins, R. A. \& StockeR, J. F. (1969) Oestrogen secretion by the rat ovary in vivo during the estrous cycle and pregnancy. Endocrinology, 85, 103. 